\title{
Editorial
}

\section{Accountability and leadership in modern corporations}

\section{Accountability e liderança na corporação moderna}

Miguel Cendoroglo Neto ${ }^{1}$, Reynaldo André Brandt ${ }^{1}$

${ }^{1}$ Hospital Israelita Albert Einstein - HIAE, São Paulo (SP), Brazil.

The growth of hospitals in size and complexity in the last three decades led to a trend of professionalizing their management, by adopting practices and systems of other areas and industries. This convergence brought new challenges as hospitals become companies and corporations.

The corporate scandals of the 1990's, such as that of Enron Corporation, and in 2000, the example of Fannie Mae and Freddie Mac, forced the society to reconsider its scope of responsibility, or better, the accountability of leaders in organizations. In a modern company, the leadership and all others involved are expected to be concerned not only about the immediate financial result, but mainly about adding value to all stakeholders. Stakeholders are not only shareholders, but also the clients and consumers of products and services of the company, its employees, its suppliers and partners, and the remaining society. This explains the current concern of organizations about sustainability of the society and the environment.

This increased scope of responsibility in today's society requires reflections on the role, attitude and awareness of the companies' leaderships. A continued revision of ethics is needed, mainly taking into account the ground rules and local ethics codes, which are crucial but not enough to assure the best decisions.
As workers move from technologists to knowledge workers, we increasingly depend on their decisions, making organizational culture a core subject. At present, it is not only the managerial leadership of the organizations that represents a barrier to errors and adverse events, but primarily the worker, which makes the organization co-responsible for the results. The leadership, in turn, should aim to understand, promote and underline the values and strengths of the organizational culture.

As part of the group of companies that comprise the social tissue, hospitals are expected to do to more than generating products and services. Society expects not only added value for aiming at cure, but caring for patients, with compassion and promoting health in the community. Although there are clear limits related to healthcare costs, receptiveness and humanization attitudes are always expected. In this context of a more complex world and further expectations regarding hospitals and healthcare services, we should direct our organization. In other words, in our organization we hope we have more than control levels and compliance of large international companies.

In this issue of einstein, the article by Santos et al.(1), "Compliance and leadership: the susceptibility of leaders to the risk of corruption in organizations", does not address specifically accountability 
of governance in hospitals and healthcare services, but it provides relevant information on the topic in current corporations, discussing the challenges in a new context. The data were provided by the ICTS Global, an international company specialized in reducing risks in equity, reputation, information and life, including prevention of frauds and losses. The survey demonstrates that leaders of the included companies are more willing to break compliance rules than those subject to the leader. On the other hand, the leaders show more loyalty to their organizations. A possible interpretation would be that the leaders, motivated by loyalty to their companies, would be more likely to not comply with their own principles.

Back to the context of hospitals in this new corporate world, we should first consider that a possible manner to not complying with the principles would be searching to achieve short-term results, particularly financial results. However, in discussing corporate accountability, the importance of long-term goals is increasingly emphasized, focused on clients, employees and the image for the society. Second, as regards to hospitals and healthcare services, the debate about accountability and ethics is even more comprehensive and deeper, and the value of health is above any other issues, even when addressing at the individual level. What is ethical to do with patients has priority in the debate, and other matters are in a secondary plan.
Nonetheless, it is clear in the article by Santos et al. ${ }^{(1)}$, that the trend of top managers to damage their own personal principles in order to adjust to requirements of the company, particularly to financial results, and, therefore be loyal to the business guidelines, set a paradoxical situation as well as emotional tension for these managers. This would not happen if personal principles and those of the organizations were the same and were sincere and transparent. That is the case of some principles adopted by the Hospital Israelita Albert Einstein, as well as by the Institute of Medicine, in general, and the basic principle stating the needs of patients rank first.

The discussion put forward by Santos et al. ${ }^{(1)}$ incite us to go deeper in this debate at hospitals, contextualizing the expectations of our society as to leadership of large organizations of modern society, as well as the role played by hospitals and healthcare services in this society and accountability of their leaders. It stands out in einstein as an invitation for us to reflect, and to other investigations and publications as a way to express accountability of our organization in the current Brazilian scenario.

\section{REFERENCE}

1. Santos RA, Guevara AJ, Amorim MC, Ferraz-Neto BH. Compliance and leadership: the susceptibility of leaders to the risk of corruption in organizations. einstein. 2012;10(1):1-10. 